\title{
La Biblioteca Popular Juventud Moderna: el grupo teatral 'Amigos del Arte', sindicatos y sociabilidad. Mar del Plata, Argentina, 1939-1947
}

Doi: $10.25100 /$ hye.v14i51.6987

Artículo recibido: 06-02-2018 | Artículo aceptado: 10-05-2018

\section{Milagros Dolabani}

Licenciada en Sociología, Universidad Nacional de Mar del Plata (Argentina). Bachiller en Ciencias Sociales, Insitituto Modelo Santa Teresita, Partido de La Costa, Provincia de Buenos Aires. Integrante del Grupo de Investigación Movimientos Sociales y Sitemas políticos en la Argentin Moderna (GIMSSPAM), perteneciente al Centro de Estudios Históricos (CEHis) de la Universidad Nacional Mar del Plata. Correo electrónico: milagros.dola@gmail.com

Forma de citar este artículo: Dolabani, Milagros. "La Biblioteca Popular Juventud Moderna: el grupo teatral 'Amigos del Arte', sindicatos y sociabilidad. Mar del Plata, Argentina, 1939-1947”. Historia y Espacio, vol. 14, nº 51 (2018): 135-163. Doi: 10.25100/hye.v14i51.6987.

Artículo Tipo 1: de investigación. 


\section{La Biblioteca Popular Juventud Moderna: el grupo teatral 'Amigos del Arte', sindicatos y sociabilidad. Mar del Plata, Argentina, 1939-1947}

Resumen: A lo largo del presente trabajo describiremos las actividades artísticas del grupo filodramático "Amigos del Arte", perteneciente a la Biblioteca Popular Juventud Moderna (BPJM), entidad fundada en 1911 en Mar del Plata, Argentina, donde también se reunían los gremios autónomos agrupados en la Unión Obrera Local (UOL). Nos centraremos en el período de actividad de la agrupación, entre 1939 y 1947, rastreando allí los momentos relevantes tanto para el grupo filodramático como para la asociación que lo cobijaba. Asimismo a través del análisis de su labor teatral, intentaremos observar la yuxtaposición de las múltiples actividades que se daban en su seno: militancia gremial y política, actividades recreativas y de esparcimiento, junto a la labor de difusión cultural propia de la biblioteca.

Palabras clave: Biblioteca popular, teatro-anarquismo, Mar del Plata.

\section{The Popular Library "Juventud Moderna": the theatrical group Amigos del Arte', unions and sociability. Mar del Plata, Argentina, 1939-1947}

Abstract: Throughout this work we will describe the artistic activities of the philodramatic group "Amigos del Arte", belonging to the popular library "Juventud Moderna", an entity founded in 1911 in Mar del Plata, Argentine, where the autonomous unions grouped in the local workers' unión, also met "Unión Obrera Local". We will focus on the period of activity of the group, between 1939 and 1947, tracing the relevant moments there for both: the philodramatic group and the association that sheltered it. Also, through the analysis of their theatrical work, we will try to observe the juxtaposition of the multiple activities that took place within them: union and political militancy, recreational and leisure activities, together with the work of cultural diffusion characteristic of the library.

Keywords: popular library, theather, anarchism, Mar del Plata. 


\section{La Biblioteca Popular Juventud Moderna: el grupo teatral 'Amigos del Arte', sindicatos y sociabilidad. Mar del Plata, Argentina, 1939- 1947}

\section{Introducción}

Fundada en Mar del Plata, Argentina, en el año 1911 por grupos ligados al movimiento anarquista, la Biblioteca Popular Juventud Moderna (BPJM) contó con el despliegue de múltiples actividades con motivaciones que en diversas circunstancias se enlazaban, pero que también superaban sus fines gremiales o políticos. Entre sus variados propósitos perseguía disputar el tiempo libre de los trabajadores y trabajadoras que allí acudían, efectuando distintas actividades culturales y de esparcimiento como la organización de conferencias o la realización de pícnics, actividades habituales dentro de la tradición de promoción cultural anarquista entre fines del siglo XIX y la primera mitad del siglo $\mathrm{XX}^{1}$.

La BPJM constituía un espacio que superaba los fines estrictamente bibliotecarios, donde las prácticas ligadas a la militancia gremial y política convergían junto a las del esparcimiento y sociabilidad. En ese sentido, la presencia de grupos de teatro vocacional o filodramáticos era habitual en la institución, actividad cultural también frecuente dentro de las múltiples

1 Nicolás Quiroga, "Prácticas políticas y cambio cultural: anarquistas autodidactas hacia mediados de 1940", Estudios Ibero-americanos, vol. 30, n. ${ }^{\circ} 1$ (2004): 139-160. 
instituciones y asociaciones ligadas a las izquierdas de nuestro país durante la primera mitad del siglo XX.

En nuestro caso, nos centraremos en el análisis del grupo filodramático "Amigos del Arte", agrupación artística conformada por jóvenes activistas que también se desempeñaban como socios de la BPJM o como delegados de los gremios que allí tenían lugar, durante finales de la década de 1930 hasta mediados de la siguiente. En palabras de uno de sus protagonistas, el grupo filodramático tenía "[...] a su cargo la faz recreativa, la que debía desarrollarse con un sentido cultural de manera que coadyuvara en la acción emancipadora que llevaba a cabo la biblioteca"2.

El presente trabajo, inscripto dentro de la redacción de tesis de Licenciatura en sociología de la autora, tomará la actividad teatral del conjunto filodramático como un punto de partida a través del cual visualizar la yuxtaposición entre prácticas políticas, sociales y de esparcimiento dentro de una institución y de un contexto socio histórico en el que estaban reconfigurándose. En efecto, recorreremos los años que van desde la gestación de la agrupación en 1939, hasta el momento en que las actividades que tenían lugar en la biblioteca llegan a su fin, tras la clausura de la institución a finales de 1947.

La selección de ese periodo temporal, por su parte, requiere que una serie de intercambios académicos sobre la presencia del anarquismo en Argentina sean retomados, particularmente aquellos que tuvieron como eje de discusión el periodo de vigencia del movimiento, así como su incidencia sobre el movimiento obrero organizado, y su presencia dentro del territorio nacional. A este respecto, algunos de los estudios más resonantes en el área se centraron en los registros de la ciudad de Buenos Aires y en temporalidades cercanas al Centenario de la República, postulando a ese momento histórico y a las dos décadas subsiguientes como el umbral que el anarquismo no pudo traspasar. Trabajos como los de Juan Suriano o Dora Barrancos, han propuesto a los años que recorren desde finales del siglo XIX hasta las décadas de 1910, 1920 y 1930 como el espacio temporal en el que la actividad del movimiento tuvo su auge y caída ${ }^{3}$. Suriano analizó cómo la importante presencia del anarquismo no pudo sortear las transformaciones sociales, políticas y culturales gestadas a principios del siglo XX, marcando como hito de su declive la sanción de la ley

2 Héctor Woollands, Recuerdos de un militante anarquista (Mar del Plata: Grupo Editor el Martillo, 1999), 37.

3 Dora Barrancos, Anarquismo, educación y costumbres en la Argentina de principios de siglo (Buenos Aires: Editorial Contrapunto, 1990). 
electoral de 1912, la que ampliaba la participación política ciudadana mediante el sufragio universal, secreto y obligatorio ${ }^{4}$. Asimismo el notable crecimiento y la diversificación de las industrias culturales explican en parte el detrimento de la influencia de las alternativas culturales anarquistas ${ }^{5}$, sumado a la aparición de otras expresiones políticas y gremiales que disputaron su influencia en el movimiento obrero ${ }^{6}$.

No obstante, una serie de investigaciones han objetado la periodización aludida, puntualmente al Centenario de la República como el punto de inflexión en el accionar del movimiento. Migueláñez Martínez ha señalado a esa fecha, 1910, como "una fractura en los estudios del anarquismo argentino" explicada en parte por la centralidad del peronismo dentro de los estudios históricos en el país, por los criterios de "éxito o fracaso" que la historiografía argentina ha utilizado para efectuar sus investigaciones, así como por la agenda seguida por la historiografía marxista que, vía Eric Hobsbawm, vio al movimiento libertario como parte de vestigios salvajes de tradiciones arcaicas. Agustín Nieto a ese respecto, sostuvo que la conformación de cierto "sentido común historiográfico" ${ }^{8}$ contribuyó a obnubilar el desarrollo de investigaciones más allá de lo ocurrido en la ciudad de Buenos Aires, cuyos registros y resultados fueron extrapolados hacia el resto del país, ignorando experiencias que trascendieran esos límites geográficos. Esas investigaciones sobre el "anarquismo argentino", se limitaron al estudio de la central obrera de

4 Juan Suriano, "La reforma electoral de 1912 y la impugnación anarquista”, Estudios Sociales, vol.43, n. ${ }^{\circ} 1$ (2012): 91-104.

5 Juan Suriano, "Las prácticas culturales del anarquismo argentino", Trabajo presentado en el Encuentro Cultura y Práctica del Anarquismo, desde sus orígenes hasta la Primera Guerra Mundial, Cátedra México-España del Colegio de México, 23 y 24 de marzo de 2011, "Federación Libertaria Argentina" (2011), URL: http://www.federacionlibertaria.org/BAEL/ Archivo/Tesis,\%20monografias/Suriano\%20=\%20Pr\%C3\%A1cticas\%20culturales\%20 -\%20Argentina.pdf. Consultado el 21 de mayo de 2018.

6 Suriano, "La reforma electoral de 1912", 91-104.

7 María Migueláñez Martínez "1910 y el declive del anarquismo argentino. ¿Hito histórico o hito historiográfico?”. XIV Encuentro de Latinoamericanistas Españoles: congreso internacional, Santiago de Compostela, España. Compilado por Rey Tristán, Eduardo y Calvo González, Patricia. Universidad de Santiago de Compostela, Centro Interdisciplinario de Estudios Americanistas Gumersindo Busto, Consejo Español de Estudios Iberoamericanos, Sciences de l'Homme et de la Société (2010): 436-452, URL: https://halshs.archives-ouvertes. $\mathrm{fr} /$ halshs-00529699.

8 Agustín Nieto, "Notas críticas en torno al sentido común historiográfico sobre 'el anarquismo argentino", A Contracorriente, vol.7, n. ${ }^{\circ} 3$ (2010): 219-248. 
raigambre anarquista, la Federación Obrera Regional Argentina (FORA), y a los registros de su órgano de difusión, el periódico La Protesta ${ }^{9}$.

En esa línea de análisis, trabajos como los de Osvaldo Graciano ${ }^{10}$, María Bordagaray $^{11}$ y nuevamente, Agustín Nieto ${ }^{12}$, muestran que la presencia del movimiento persistió a pesar de la caída de la influencia de la FORA tras el golpe de estado de 1930. Las iniciativas editoriales y la escritura sobre la realidad argentina y mundial; el enrolamiento de las mujeres, los universitarios y la juventud además de los obreros, como corolario de la fundación de la Federación Anarco Comunista Argentina (FACA) en 1935, constituyeron intentos de renovación en sus actividades y tácticas respecto a la movilización política y sindical de las décadas de 1930 y 1940. López Trujillo se centró también en el lapso temporal aludido, indagando sobre la presencia del anarquismo en la denominada "década infame" - entre 1930 y 1943- en particular, sus intentos de organización mediante el análisis de la constitución del Comité Regional de Relaciones Anarquistas (CRRA) en 1932, y su accionar posterior, con la organización de la FACA ${ }^{13}$.

Teniendo presente dichos debates y considerando que nuestro periodo de interés se centra más allá del umbral espacio-temporal propuesto por aquellas investigaciones "clásicas", nuestros propósitos de investigación buscan analizar la vida artística del grupo filodramático "Amigos del Arte" atendiendo a sus vinculaciones con los momentos relevantes para el colectivo, así como con otras entidades, grupos o instituciones presentes en el contexto histórico delimitado. Mediante el análisis de un universo heterogéneo de fuentes, y a partir de dichas vinculaciones, creemos pertinente observar las superposiciones entre militancia gremial, política y cultural, dentro de un espacio en el que, a pesar de diferenciarse externamente, muchas veces se encontraban imbricadas.

9 Ibíd.

${ }^{10}$ Osvaldo Graciano, "La escritura de la realidad. Un análisis de la tarea editorial y del trabajo intelectual del Anarquismo argentino entre los años 30 y el Peronismo", Revista Izquierdas, n. 12 (2012): 72-110, URL: http://awww.izquierdas.cl/ediciones/2012/numero-12-abril.

11 María Eugenia Bordagaray, “Controversias libertarias", La interpelación anarquista en tiempos del anarquismo, Tesis de Posgrado Universidad Nacional de La Plata, Facultad de Humanidades y Ciencias de la Educación, 2014, 1-254.

${ }^{12}$ Agustín Nieto, "Conflictividad obrera en el puerto de Mar del Plata: del anarquismo al peronismo. El Sindicato Obrero de la Industria del Pescado, 1942-1948”, Revista de Estudios Marítimos y Sociales, n. ${ }^{\circ} 1$ (2008): 35- 44.

${ }^{13}$ Fernando López Trujillo, Vidas en rojo ynegro. Una historia del anarquismo en la "Década infame", (Buenos Aires: Letraa libre, 2005), 1-258. 
Asimismo, al centrarnos en el análisis de ámbitos sociales "bajos", para la concreción de nuestros propósitos resulta pertinente adoptar perspectivas de investigación basadas en el análisis microhistórico

basados en la convicción de que el carácter intensivo del proceder microanalítico tiene como mérito principal el de ayudarnos a comprender mejor el entramado de las lógicas sociales, resiste mejor también a la tentación de una reificación de las acciones y de las relaciones, así como de las categorías que nos permiten pensarlas ${ }^{14}$.

El análisis de fuentes primarias compuestas por los libros de actas de la comisión administrativa de la biblioteca, y el relevamiento de periódicos editados durante el período de interés, conforman el universo de referencias consultado, complementándolo con la consulta de memorias, testimonios y autobiografías, aportando información o reflexiones sobre todos aquellos temas "menores" que habitualmente quedan fuera de las historias tradicionales ${ }^{15}$.

Ateniéndonos a lo específico de nuestro objeto de estudio, sostenemos que el análisis teatral está subordinado a la relevancia del contexto en el que las agrupaciones teatrales ligadas a movimientos políticos se desempeñaban, y es allí donde deben rastrearse las cuestiones relativas al carácter de las funciones teatrales y las puestas en escena. Siguiendo esa premisa, intentamos superar los posicionamientos abocados solo al análisis de los textos dramáticos utilizados y al hecho teatral en sí mismo, posicionamientos imperantes en décadas anteriores y que eludían el contexto en el cual el hecho teatral era gestado y representado ${ }^{16}$. En ese sentido consideramos que toda producción cultural debe ser abordada en tanto experiencia, superando los límites propios de la práctica teatral, y extendiéndose desde y hacia lo social, haciendo hincapié en sus condiciones de producción y de recepción, pues recuperar una "historia

${ }^{14}$ Jacques Revel, Juegos de escala. Experiencias de microanálisis (Buenos Aires: UNSAM edita, 2015), 16.

${ }^{15}$ Horacio Tarcus, "Las izquierdas argentinas en el siglo XX. Una aproximación metodológica”, en Aportes para una Argentina plural (Buenos Aires: Archivo General de la Nación, 1999), 97-115.

${ }^{16}$ Lorena Verzero, "Hacia una historia material de las prácticas teatrales anarquistas”, en En las tablas libertarias. Experiencias de teatro anarquista en Argentina a lo largo del siglo XX. Editado y compilado por Lorena Verzero sobre textos de Carlos Fos (Buenos Aires: Atuel, 2010), $15-32$. 
material" del teatro anarquista remite a recuperar el entramado social del que forma parte ${ }^{17}$.

Es así que en un primer momento indagaremos en la conformación del conjunto filodramático, sus vínculos con la BPJM y con otros espacios de participación de sus miembros, así como su composición interna a lo largo de nuestra periodización. Luego nos concentraremos en la actividad de Amigos del Arte, análisis efectuado mediante la discriminación de las fechas en que realizaban sus funciones para así observar su relación con los momentos relevantes para el colectivo. Al indagar en el momento y lugar que escogían para desplegar sus actividades, también rastrearemos sus conexiones con otras instituciones o agrupaciones que por ese entonces tenían presencia en el panorama gremial, político y social de la ciudad y la zona.

\section{La Biblioteca Popular Juventud Moderna en el contexto socio histórico marplatense}

Fundada bajo el nombre de Sociedad Instructiva y Recreativa Juventud Moderna en noviembre de 1911 por un grupo de hombres partidarios del ideario anarquista, simpatizantes del socialismo y en menor medida pertenecientes a la corriente sindicalista que actuaban en los gremios de la ciudad, luego sería renombrada como Biblioteca Popular Juventud Moderna (BPJM), constituyendo la primera biblioteca local. Por aquel entonces Mar del Plata era una ciudad que, tras ser fundada a fines del siglo XIX por miembros de la oligarquía terrateniente, su ubicación a $400 \mathrm{~km}$ de la ciudad de Buenos Aires sobre la costa argentina la convertía en un destino de veraneo privilegiado para la elite nacional. Aunque en un inicio sus actividades económicas se ligaron a la vigencia del modelo agro exportador, a principios del siglo XX comienza a instaurarse como lujosa villa balnearia de la acaudalada oligarquía terrateniente, transformándose en la "Biarritz argentina" e imprimiéndole un ritmo de vida signado por el comienzo y el final de la temporada de verano.

La otra cara de Mar del Plata la componían los pobladores que residían todo el año, trabajadores que concurrían a la BPJM a participar de los primeros sindicatos locales que allí tenían su sede, o bien de las distintas actividades culturales efectuadas, como la realización de conferencias científicas y

${ }^{17}$ Verzero, Lorena. "Políticas de la investigación en teatro político", Territorio teatral revista digital, n. 9 (2013): 1-8. 
filosóficas ${ }^{18}$. Desde su fundación y al carecer de un espacio propio, los socios y militantes que participaban de la biblioteca debieron alquilar distintos locales para desarrollar sus actividades, para en 1922 adquirir un terreno propio donde erigirían su sede definitiva, ubicada muy cerca del centro cívico y comercial marplatense, en la intersección de las calles Bolívar y Diagonal Pueyrredón. La mudanza y la posterior inauguración de la nueva sede en 1924 se debió -según las notas trazadas sobre la historia de la BPJM por el militante y actor vocacional Héctor Woollands- a la negativa de los propietarios de diversos locales de la ciudad a tener a los sindicatos como locatarios, pues "la acción de los sindicatos obreros en aquellos tiempos era vista con animosidad por las gentes de clase media” ${ }^{19}$. Esa situación llevó a que se discutiera la adquisición de un terreno propio, no sin antes superar la resistencia de muchos de sus socios, que veían en ello una cuestión de principios al oponerse a la propiedad privada. Asimismo en 1922 también se da lugar el primer conjunto filodramático de la asociación, agrupación denominada "Juventud Moderna” y que tendría actuación hasta el año 1925.

Por su parte aquel escenario de reunión de la opulencia criolla que le dio forma a la ciudad en las primeras décadas del siglo XX, quedará vacío con el crack del 29 y con la recesión del comercio internacional, sumado al golpe de estado en septiembre de 1930 efectuado por el militar José Félix Uriburu. Dicha coyuntura fue el punto final para la Mar del Plata de las confiterías, los grandes hoteles y los paseos por la Rambla, espacios donde la elite nacional se codeaba con las personalidades más destacadas de la cultura, la política y los negocios. A partir de ese entonces, el viraje del modelo económico nacional de agro-exportador hacia la denominada Industrialización por Sustitución de Importaciones (ISI), implicará que la ciudad dé un giro con respecto a su perfil de villa balnearia, pasando de lugar de veraneo privilegiado de la oligarquía nacional, a de quienes se beneficiarían con la ISI, para finalmente convertirse en balneario de masas durante los años del primer peronismo, cuando las vacaciones se instituyan como derecho y dejen de ser un privilegio de las elites ${ }^{20}$.

${ }^{18}$ Gustavo Dorado, Lucas González, Oscar Spadari, Entre bibliotecas y andamios. Orígenes del movimiento obrero en Mar del Plata (1890-1930) (Mar del Plata: Suárez, 2013).

${ }^{19}$ Héctor Woollands Notas para la historia de la Biblioteca Popular Juventud Moderna (Mar del Plata: Ediciones Biblioteca Popular Juventud Moderna, 1989), 23.

${ }^{20}$ Nos referimos a la adquisición de derechos del trabajador durante el primer gobierno de Juan Domingo Perón (1946-1952), puntualmente el derecho a vacaciones pagas, el que junto a una serie de medidas como la estatización del hotel provincial, y el traspaso de distintos hoteles a sindicatos, terminaron por posicionar a Mar del Plata como el balneario popular 
En cuando a la BPJM, tanto la crisis económica como la dictadura militar instaurada por la revolución septembrina, afectarían negativamente el proceso de lento crecimiento que venía desarrollando, impidiendo el normal funcionamiento de las actividades sindicales y culturales que allí se daban cita. La persecución policial y la ausencia de actividades se observan en las actas de las asambleas celebradas en la institución, donde en varias oportunidades se remarcaba la necesidad de "atraer más gremios", así como de "romper con la apatía suicida que tanto perjudica a la labor de la biblioteca. Deben darse conferencias culturales y educativas para levantar el espíritu"21.

Hacia mediados de la década del treinta no obstante, la organización política y gremial de la ciudad se verá revitalizada, emprendiendo un proceso de reactivación y modificación que afectará las características de sus formaciones gremiales, hasta entonces ancladas en las tradiciones de gremios por oficios ${ }^{22}$. La formación de una clase obrera de tipo industrial se daría hacia 1935, con la aparición de la Federación Obrera Nacional de la Construcción (FONC) y con la organización de trabajadores y trabajadoras del pescado en el Sindicato Obrero de la Industria del Pescado (SOIP) durante la década siguiente, como corolario de transformaciones más generales que trastocaron el tipo de estructura económica hasta entonces vigente ${ }^{23}$.

También en esos años comienza un periodo en el que la intervención del Estado y del Departamento Provincial del Trabajo en la relaciones laborales se hace cada vez más frecuente, regulando las condiciones laborales e imponiéndose como interlocutor obligatorio de los conflictos entre capital y trabajo ${ }^{24}$.

por excelencia de la Argentina. Elisa Pastoriza, Los trabajadores de Mar del Plata en vísperas del peronismo (Buenos Aires: Centro editor de América Latina, 1993).

21 “Actas comisión administrativa BPJM”, Mar del Plata, 15/02/1933, Archivo Biblioteca Popular Juventud Moderna (ABPJM), Mar del Plata, Argentina. Tomo I, 26.

${ }^{22}$ La clase obrera marplatense se encontraba hasta la década del treinta en estado embrionario, pues sus establecimientos fabriles eran pequeños y medianos, en su mayoría manufactureros, con un escaso capital inicial e instalaciones pequeñas acompañadas por limitados medios tecnológicos, poca diferenciación de labores y relaciones personalizadas entre obreros y patrones. Dorado, González y Spadari, Entre bibliotecas y andamios.

${ }^{23}$ Ibíd.

${ }^{24}$ Agustín Nieto, "Anarquistas negociadores. Una revisión del sentido común historiográfico sobre el 'anarquismo argentino' a la luz de algunas experiencias libertarias en el movimiento obrero, Mar del Plata 1940-1943”, En Taller de la Historia, vol.5 n. 5 (2013): 245-277. 
En esos años, además, se asiste a un incremento en la composición demográfica local, debido al crecimiento vegetativo de su población, hasta entonces compuesta en su mayoría por inmigrantes provenientes de ultramar. Asimismo junto a las nuevas generaciones de marplatenses, la población se incrementa con la llegada de importantes flujos migratorios provenientes en su mayoría de ciudades aledañas de la provincia de Buenos Aires, localidades que habían sufrido el impacto de la recesión internacional en las actividades agrícola-ganaderas, su principal soporte económico. En este sentido, la crisis del 29 y el viraje en el modelo económico nacional se manifestará en un aumento de la población económicamente activa y en el porcentaje de la población ocupada, engrosada por hombres y mujeres que arribaban a la ciudad en busca de nuevas oportunidades laborales.

A ese respecto una de las características del mundo del trabajo de aquellos años y que será una constante en los subsiguientes, fue la marcada estacionalidad en la oferta y la demanda de puestos laborales, con un mercado de trabajo signado por el inicio y el final de la temporada estival. Durante la primavera y el verano tomaba preeminencia la industria del pescado - con su auge en la temporada de anchoíta-, la actividad relativa a los servicios brindados al turismo -hotelería, gastronomía, comercios, etc.- y durante los meses de invierno la industria de la construcción. Dichas actividades eran las que atraían y reunían al mayor número de trabajadores y trabajadoras de la época, aumentando el porcentaje de población ocupada y otorgando mayor vitalidad a la vida sindical marplatense.

Es en ese contexto que se conforman nuevos sindicatos, o se da la refundación y el fortalecimiento de los preexistentes: los sindicatos por oficios se aglutinarán en la Unión Obrera Local (UOL) de gremios autónomos, entidad con sede en La Casa del Pueblo cohabitante dentro de la BPJM; y en la FONC, central de filiación comunista que reunía a los gremios por rama de actividad, en este caso, la construcción. Para el caso de la UOL y también de la BPJM “La confluencia de una nueva generación de militantes anarquistas y de una nueva generación de obreros/as dejó una profunda huella en la historia de las luchas sociales de la ciudad"25.

En ese sentido, los antecedentes que forjaron la constitución de la UOL merecen ser mencionados, puntualmente su filiación durante los primeros años de la década del treinta a la FORA del V congreso, central obrera adherente al anarco-comunismo. La Federación Obrera Local, nombre que tenía por

${ }^{25}$ Ibíd., 160. 
ese entonces, romperá relaciones con la FORA en 1935, y se alineará con la Federación Anarco Comunista Argentina (FACA) tras celebrarse su II Congreso en 1940, reconfigurándose y erigiéndose en la Unión Obrera Local (UOL) de sindicatos autónomos. Con su refundación se modificarán algunas de las lecturas efectuadas hasta el momento sobre la coyuntura política e industrial y sobre las distintas organizaciones gremiales, realizándose una crítica a no adquirir conquistas laborales por estar sancionadas legalmente -tal como primaba en sus lecturas durante los años de la FOL- así como también se caracterizará a las otras centrales obreras de alcance nacional -la Confederación General del Trabajo (CGT) y la Unión Sindical Argentina (USA)como burocráticas, y a la FORA como sectaria ${ }^{26}$. También participarían en vinculación con la FACA y la UOL las denominadas Juventudes Libertarias, órgano juvenil que con presencia en distintas localidades de la provincia de Buenos Aires ${ }^{27}$, se conformará en la ciudad hacia 1941, impulsadas por aquellos jóvenes que se iban incorporado a las actividades de la BPJM.

En cuanto a la biblioteca, las transformaciones que venimos describiendo hasta aquí también fueron imponiéndose en su interior, repercutiendo entre otras cosas, en el modo de concebir la intervención estatal en la asociación. Así lo observamos en la solicitud de una subvención cuatrimestral realizada en 1937 a la Comisión Nacional Protectora de Bibliotecas Populares ${ }^{28}$, pedido que puede leerse en una primera impresión como la necesidad de un apoyo económico para sostener la institución o, en un plano menos superficial, considerando las intenciones de los actores en cuestión por integrarse a las posibilidades que brindan la ampliación del estado. Otro indicio de cierto aggionarmiento hacia los requerimientos legales que se estaban aplicando, fue la adquisición de personería jurídica, para lo cual incluso se modificaron los estatutos que regían la institución hacia el año $1947^{29}$.

Más allá de las transformaciones y requerimientos en el plano de la legalidad, quienes sostenían la labor bibliotecaria y la comisión administrativa

${ }^{26}$ Ibíd.

27 Bordagaray, “Controversias libertarias”, 1-254.

28 “Actas comisión administrativa BPJM”, 10/03/1937, tomo I, 98.

${ }^{29}$ A ese respecto se modificaron los puntos respecto a la renovación de la comisión directiva la que debía efectuarse una vez por año en lugar de cada seis meses, la convocatoria a asambleas ordinarias y extraordinarias se debía realizar con ocho días de anticipación, y por último, la comisión administrativa debía estar compuesta por nueve miembros. "Actas comisión administrativa BPJM", 27/06/1947, tomo II, 35-38. 
también fueron receptivos hacia otro tipo de cambios en la época, como el aumento experimentado en el grado de escolarización de la población local y el concomitante descenso en las tasas de analfabetismo, hecho que repercutiría en una mayor demanda de material técnico por parte de sus socios y usuarios ${ }^{30}$. Precisamente en el año 1943 se plantea por primera vez en asamblea extraordinaria la necesidad de instalar una sección de libros para la “juventud estudiosa”, así como adquirir más libros para completar la sección infantil ${ }^{31}$, segmento hasta entonces apenas considerado por los administradores de la BPJM. Otro hecho que corre cercano al anterior, fue la incorporación de menores de edad a la categoría de socios luego de una reforma de los estatutos durante 1946, conformada hasta ese entonces solo por las categorías de socios adherentes (mayores de edad) u honoríficos (por su aporte a la institución, y exentos de contribución mensual) ${ }^{32}$.

También mediante el análisis de las actas de la comisión administrativa, observamos como una constante de esos años los pedidos de intervención de la institución en las distintas asambleas gremiales -incluso de gremios que allí no tenían parte-, hecho constatado por las notas recibidas y evaluadas en las asambleas. Esos pedidos empero, eran rechazados reiteradamente pues la comisión administrativa se empeñaba en diferenciar hacia el exterior la labor de la biblioteca-en tanto su misión cultural y educativa- con respecto a la Casa del Pueblo, a pesar de compartir el mismo edificio. Sin embargo, podemos inferir en ello el grado de relevancia que tenía la institución para el mundo obrero de la ciudad, percibiéndola no como escindida en dos espacios diferenciados, sino como una unidad a la que se acudía cuando, por ejemplo, los gremios tenían conflictos internos ${ }^{33}$.

${ }^{30}$ Nicolás Quiroga, "Lectura y política. Los lectores de la biblioteca popular juventud moderna de Mar del Plata (fines de los años treinta y principios de los cuarenta)" Anuario IEHS, n. ${ }^{\circ} 18$ (2003): 449-474.

31 “Actas comisión administrativa BPJM", 30/09/1943, tomo I, 245.

32 “Actas comisión administrativa BPJM", 02/08/1946, tomo II, 4.

${ }^{33}$ Así sucedió por ejemplo cuando, luego de que se suscitara cierto conflicto y enfrentamiento del gremio de Mozos dentro del recinto, "produciéndose incidentes que revisten importancia para la biblioteca y su moral cultural", su local es cerrado. "Actas comisión administrativa BPJM” Mar del Plata, 19/01/1935, tomo I, página 53. Luego, mediante una nota enviada por el gremio se solicita a la biblioteca que envíe dos delegados a su próxima asamblea gremial. Frente a ello la comisión administrativa decide responderles negativamente aclarando que "nada tiene que ver la biblioteca con las organizaciones". "Actas comisión administrativa BPJM”, 18/03/1935, tomo I, 69. 
Finalmente, las transformaciones que describimos y que poco a poco iban manifestándose hacia el interior de la biblioteca quedarán truncas entre otras cosas, por la presencia cada vez más relevante de la biblioteca municipal, la que competiría con la BPJM por la atracción de adherentes, apoyada en su tenencia preferencial de material técnico y escolar ${ }^{34}$. Por su parte, la influencia que la UOL había adquirido dentro del mundo obrero local y en los procesos de movilización ascendente experimentados a lo largo de la década del cuarenta ${ }^{35}$, se verá afectada por el avance del partido laborista en el ámbito político, el activismo de la CGT en el gremialismo local mediante la conducción de sindicatos existentes y la fundación de otros ${ }^{36}$, y por la negativa de la FONC a constituir una central obrera unificada que enfrentara los avances aludidos por parte del flamante movimiento peronista. Pero fundamentalmente la clausura a finales de 1947 de la Casa del Pueblo y de la BPJM efectuada por el peronismo, constituyó un punto de ruptura para las actividades que allí se desarrollaban, incluyendo la realización de conferencias, las asambleas gremiales, y las actividades culturales y artísticas efectuadas por el conjunto filodramático Amigos del Arte.

\section{Amigos del Arte: génesis de la agrupación artística}

Como parte de las transformaciones que iban desarrollándose en la Mar del Plata de mediados de los treinta y principios de los cuarenta, la fundación Amigos del Arte se inscribió en 1939 dentro de los cambios que operaron hacia el interior de la BPJM, con el ingreso de nuevas generaciones de militantes que impulsaron en ella la incorporación de distintas actividades y prácticas. Fue desde una función teatral realizada en el marco de la campaña por la liberación de los presos de Bragado $^{37}$ que el grupo comenzaría su labor, instaurándose formalmente en la BPJM hacia 1940.

${ }^{34}$ Quiroga, "Prácticas políticas y cambio cultural", 139-160.

35 Agustín Nieto "Un acercamiento 'topográfico' a la militancia” sindical libertaria en la Argentina de los años cuarenta 187-216, Anuario digital n. 24 (2012)

36 Elisa Pastoriza, Los trabajadores de Mar del Plata en vísperas del peronismo (Buenos Aires: Centro Editor de América Latina, 1993). Agustín Nieto Asociacionismo obrero y popular en la aldea, Mar del Plata (1940-1960)", en Asociaciones y política en la Argentina del siglo XX. Entre prácticas y expectativas, editado por Omar Acha y Nicolás Quiroga (Buenos Aires: Prometeo Libros, 2015), 179-201.

${ }^{37}$ La campaña Pro presos de Bragado refiere a las actividades efectuadas para la liberación de tres obreros encarcelados en aesa localidad bonaerense-Mainini, Vuotto y De Diago- en el año 1931, acusados de realizar un atentado en contra del político conservador José María 
Sin embargo, a pesar del entusiasmo que se generó entre quienes habían participado del evento, la comisión administrativa de la BPJM no apoyó de inmediato la iniciativa, como lo retratan las actas de las asambleas. En ellas aparece que el conjunto filodramático requería mediante nota unirse orgánicamente a la BPJM, pedido que la comisión administrativa rechaza decidiendo no anexarlo, pero posibilitando la utilización del local siempre que lo soliciten con antelación ${ }^{38}$. Una posible lectura de dicho rechazo puede explicarse por la reticencia que los miembros más antiguos de la institución tenían respecto a las iniciativas generadas por los jóvenes que recién se iban incorporando, tal como lo señalaba el actor vocacional Héctor Woollands respecto a su ingreso en la biblioteca en 1939 "los jóvenes que concurrían allí eran muy pocos y los compañeros mayores no eran proclives a brindar su amistad y cordialidad a los recién llegados, sino que al contrario observaban con actitud de reserva y distanciamiento hacia los muchachos que nos acercábamos tímidamente a las actitudes que tenían lugar en la casa” ${ }^{39}$.

En ese sentido los miembros de Amigos del Arte eran parte de aquellos jóvenes que se habían incorporado a la institución durante mediados y finales de la década del treinta, muchos de ellos migrantes provenientes de ciudades cercanas a Mar del Plata. La composición de la agrupación oscilaba en el número de miembros, manteniéndose la presencia de algunos a lo largo de los años de actividad, al tiempo que nuevos integrantes se sumaban esporádicamente en una o dos funciones, o bien otros desistían de participar luego de alguna intervención aislada. El núcleo de fundadores, según el testimonio de Woollands, lo integraban las siguientes personas "Miguel Cangelaro, José Morales, Mario Penone, Redentor González, Ramiro Valiño Cedrón, Juan Mouilá, Francis Marcos, Leonor y Ignacio Echeve, Albano García y su esposa María Alberdi, Santiago Pourxet, José Abel Salgado, Alberto Pacheco y su señora Tertumis Acosta"40.

Así también lo observamos en los periódicos relevados, que difundían las funciones a realizarse con sus respectivos elencos, por lo que podemos caracterizar a los dos primeros años de actividad, 1940 y 1941, como "periodo

Blanch. Por ese entonces la causa había sido reabierta, gracias a la agitación y las campañas efectuadas a lo largo del país para liberar a los "Sacco y Vanzetti argentinos", reactivando asimismo la organización política en los años posteriores al golpe de estado de 1930.

38 “Actas comisión administrativa BPJM", 26/11/1940, tomo I, 123.

${ }^{39}$ Woollands, Recuerdos de un militante anarquista, 36.

${ }^{40}$ Ibíd., 38. 
de conformación”, pues en esos años su constitución y organización interna estuvo signada por la inestabilidad de sus componentes.

Será desde la ampliación del edificio de la sede, mediante la construcción de un espacio de usos múltiples -el "salón de actos"- en 1942, que se sumarán algunos miembros cuya presencia persistirá hasta el final de nuestra periodización, como las hermanas Gloria y Tota Woollands -hermanas de Héctor-, Raúl García, Jorge Vidal, Santiago Pourxet, las también hermanas Estrella y Piedad García - esta última, esposa de Héctor Woollands-, Tito Morales, Alfredo Dalmasso y Prometeo Martínez.

De lo expuesto se desprende la importancia de la dimensión material en su labor, pues desde ese entonces nuevos integrantes pasan a ser parte estable de la agrupación, mientras que el número de miembros que participaban esporádicamente se reduce, adquiriendo una mayor consistencia interna. Otro rasgo en la composición de la agrupación es la presencia de miembros unidos por lazos familiares, sean sanguíneos o políticos, arrojándonos indicios sobre el carácter endogámico y familiar hacia el interior del grupo, donde se entrecruzaban vínculos que superaban a los de camaradería en sentido estricto, algo habitual también en otras organizaciones ${ }^{41}$.

Asimismo existieron otros componentes del grupo filodramático que, sin estar arriba del escenario, también colaboraron activamente dentro de la técnica de las puestas en escena. Allí se desempeñaban compañeros de la biblioteca cuyos oficios ponían al servicio de la labor del conjunto filodramático al tratarse de un grupo amateur, como por ejemplo Roberto Crocitto, quien de oficio pintor tenía a su cargo la decoración y la realización de escenografías, o bien su hermano Erasmo, electricista, quien efectuaba los arreglos de luces y electricidad ${ }^{42}$. La participación de dichos componentes revela también la yuxtaposición que se daba en el seno de la agrupación entre la militancia cultural y la sindical, superposición mediada en este caso por vínculos familiares y de camaradería.

En ese sentido, resulta pertinente observar los otros espacios donde varios de los componentes de Amigos del Arte también se desempeñaban, vinculándose a la UOL y la BPJM. Por un lado las Juventudes Libertarias

${ }^{41}$ María Liliana Da Orden, “¿Prácticas tradicionales en un partido moderno? Socialismo y poder local, Mar del Plata, 1916-1929” en La construcción de las democracias Rioplatenses Proyectos institucionales y prácticas políticas, 1900-1930, editado por Fernando Devoto y María Ferrari (Buenos Aires: Editorial Biblos, 1994), 229-246.

42 Woollands, Recuerdos de un militante anarquista. 
agrupaban tanto a los actores vocacionales como a quienes se desempeñaban en la parte técnica de la labor teatral, dentro de los que podemos mencionar a Héctor Woollands, Miguel Cangelaro, Lolo Ferreiro, José A. Salgado, Piedad García, Prometeo Martínez, José Morales y Erasmo Crocitto. Algunos de ellos serán quienes funden la agrupación, en estrecha vinculación con el "Comité Juvenil Sindical de Ayuda y Defensa a los Presos de Bragado" ${ }^{43}$, comisión creada por los jóvenes para colaborar en la señalada campaña, dependiente a su vez del comité establecido para esos fines por los militantes de la UOL.

Por su parte y en el transcurso de los años investigados, en el ámbito gremial también se irían desempeñando algunos de los actores y actrices del conjunto filodramático, o bien a partir de su vinculación con la UOL empezarían a participar de la agrupación artística; ejemplo de esa doble pertenencia fueron Alfredo Dalmasso, Raúl García, Tota Woollands, Miguel Cangelaro y Piedad García.

Finalizando el presente apartado, destacamos la múltiple intervención de los miembros de Amigos del Arte en las distintas actividades y organizaciones que coexistían dentro del mismo espacio de participación. En principio destacamos la vinculación entre las Juventudes Libertarias y el grupo de teatro, pues además de superponerse los espacios de participación de sus miembros, es desde la función realizada por el Comité Juvenil Pro-presos de Bragado, que deciden establecerse formalmente, función que puede caracterizarse como el "mito fundante" de la agrupación artística. A su vez, las dos agrupaciones se vincularon con la UOL y con algunos de los gremios allí reunidos, principalmente el sindicato de la industria del pescado (SOIP), fundado en 1942 con una participación activa de las Juventudes Libertarias y con el apoyo de la Casa del Pueblo ${ }^{44}$. De este modo observamos como la militancia gremial y cultural dentro de la BPJM se encontraba vinculada, a pesar de los intentos de diferenciar ambos espacios por parte de la comisión administrativa. La yuxtaposición de esas labores empero, no estaba signada solo por la pertenencia múltiple de los componentes del grupo filodramático sino también, como veremos más adelante, por el tipo de campañas y causas apoyadas con su actividad.

${ }^{43}$ Nieto, "Conflictividad obrera en el puerto", 35-44.

${ }^{44}$ Ibíd. 


\section{Las puestas en escena de Amigos de Arte: funciones a beneficio, ocio recreativo y conmemoración del Primero de mayo}

Concentrándonos en la labor teatral de la agrupación, nos dirigiremos a analizar sus puestas en escena, considerando las vinculaciones con otras entidades externas a la BPJM, así como las fechas en que efectuaban sus actividades, teniendo presente las transformaciones experimentadas en el contexto de investigación.

A ese respecto reiteramos que el grupo filodramático se constituye casi al unísono que la Unión Obrera Local -uno en 1939 y la otra en 1940- y que esta, a su vez, lo hizo en el marco de su alineación con la FACA y de la ruptura con la FORA del V Congreso. En ese sentido es importante volver sobre este tema porque consideramos que ambas dimensiones se encontraban interconectadas, y como vemos, dicha conexión imprimió una impronta específica tanto en el accionar del grupo filodramático como en la política gremial desarrollada por la FACA, impronta que buscaba ampliar su campo de acción, adaptándose en algunos casos a las transformaciones que en esos ámbitos se estaban gestando.

\section{Las veladas artísticas del primero de mayo}

Dirigiéndonos al análisis de las funciones desarrolladas por Amigos del Arte, observamos a lo largo de nuestra periodización y como una constante en la realización de su actividad teatral, la conmemoración del Primero de mayo, evento tradicional no solo para la agrupación, sino dentro del movimiento obrero en general, y del anarquismo en particular ${ }^{45}$. Aunque en trabajos previos hemos indagado con más detalle la conmemoración de dicha efeméride ${ }^{46}$, mencionaremos algunos de sus aspectos más sobresalientes para los fines aquí perseguidos.

En primer término las denominadas “veladas teatrales" eran eventos que, en el marco del Primero de mayo, incluían la realización de distintas expresiones culturales y artísticas que contenían, además de la realización de obras teatrales, la recitación de “diálogos en verso", la ejecución de conciertos efectuados con

45 Juan Suriano, "Banderas, héroes y fiestas proletarias. Ritualidad y simbología anarquista a comienzos de siglo”, Boletín número 15 del Instituto de historia argentina y americana Dr. Emilio Ravignani 3ra serie (Universidad de Buenos Aires: Fondo de Cultura Económica, 1er semestre de 1997), 71-100.

46 Milagros Dolabani, "El teatro en los festejos anarquistas del primero de mayo: entre la conmemoración y el ocio recreativo (Mar del Plata, 1939-1947)”, Revista Izquierdas, n. 36 (2017): 181-199, URL: http://www.izquierdas.cl/images/html/n36/index36.html 
guitarras criollas, y en algunas ocasiones, la realización de conferencias con personalidades invitadas por la institución.

Las veladas eran eventos que se efectuaban las noches del 30 de abril, en la víspera del día del trabajador, mientras que durante la mañana del Primero de mayo se realizaban los típicos actos públicos, basados en concentraciones o mítines en las calles céntricas de la ciudad, muy cerca de la biblioteca. Así sucedía en 1942 cuando se anunciaban ambos eventos por separado en el periódico del partido socialista local, El trabajo, cuya publicación se titulaba "Conmemoración del primero de mayo" y se divulgaba del siguiente modo: "Como se ha venido anunciando la Unión Obrera Local, efectuará un gran acto de protesta el próximo viernes 1 de Mayo en la intersección de Luro y Pueyrredón, en el que harán uso de la palabra además de los oradores locales nombrados por las organizaciones obreras, el delegado de la capital federal, ciudadano Varone" 47 .

Debajo de la citada nota, se anunciaba en otro recuadro la realización de una "Velada teatral en la casa del pueblo" la que "[...] se efectuará el próximo jueves 30, a la 21.15 en punto en el salón de actos de la Biblioteca Popular Juventud Moderna, conmemorando la fecha del primero de mayo y cuyo programa estará a cargo de la Agrupación Artística Amigos del Arte [...]”48

De igual forma, las veladas se efectuaban en el contexto de un día no laboral, pues el primero de mayo es declarado feriado en nuestro país desde 1925, y se cobraba entrada general a $\$ 1$ mientras que los menores de 12 años entraban gratuitamente. En ello podemos inferir, además del propósito de recaudar dinero para la institución mediante el cobro de entradas, el perfil familiar del evento, puesto que los asistentes podrían acudir con sus familias en el contexto de un día feriado, sumado a la presencia de elementos festivos, como se anunciaba en 1946 "la velada finalizará con un fin de fiesta a cargo de todos los integrantes de la agrupación artística" ${ }^{49}$.

Otro de los componentes que durante los años relevados se reiteraba, era el uso del salón de actos a partir de su inauguración hacia finales del año 1941, convocándose del siguiente modo en la prensa de la época durante 1947: "Patrocinado por la Unión Obrera Local se llevará a cabo el 30 del corriente

\footnotetext{
47 “Periódico El Trabajo”, Mar del Plata, 28/04/1942, Archivo Histórico Municipal General Pueyrredón (AHMGP) Mar del Plata, Argentina.

48 Ibíd.

49 “Periódico El trabajo”, 30/04/1946.
} 
mes, en el salón de actos de la Casa del Pueblo, un gran festival teatral con la actuación escénica de la Agrupación Artística Amigos del Arte"50.

En cuanto al carácter de las obras representadas, es interesante destacar que no siempre referían a temáticas ligadas a la conmemoración de la fecha, utilizando textos y autores que no se asociaban directamente con fines proselitistas, destacándose "Hijos del Pueblo" del periodista y militante libertario Rodolfo González Pacheco, como la única obra representada que iba en ese sentido ${ }^{51}$. Este aspecto resulta importante de mencionar puesto que gran parte de la bibliografía sobre teatro anarquista se asocia al contenido de los mensajes presente en los textos dramáticos utilizados, con el propósito de "esparcir el ideal libertario" en contraposición al teatro comercial o burgués, como elemento de transformación social que se añadía a las otras herramientas utilizadas con ese propósito por el movimiento ${ }^{52}$.

Para nuestro caso, el carácter de su realización en un día feriado, dentro de un horario nocturno, en un ámbito familiar, sumado al contenido de los textos utilizados para las representaciones, así como la presencia de elementos festivos, nos invitan a pensar en las veladas o festivales teatrales como un momento de recreación, más allá de la finalidad explícita de conmemorar el día del trabajador. No obstante, considerando las críticas más tradicionales esgrimidas por el anarquismo respecto a la caracterización de festividad de la fecha realizada por el Partido Socialista y más tarde, el comunista ${ }^{53}$, podría objetarse que las veladas poseían un sentido contradictorio con respecto a esa

50 "Periódico El Trabajo", 19/04/1947.

${ }^{51}$ Dicha obra se representó en la velada artística del primero de mayo de 1945. "Periódico El Trabajo”, 26/04/1945. Para un mayor detalle de las obras puestas en escena por Amigos del Arte véase Milagros Dolabani, "El repertorio teatral de Amigos del Arte: entre la cultura anarquista’ y la 'cultura de masas'. Mar del Plata 1939-1947”, Revista Páginas Vol. 9, nº 20 (2017): 147-168.

${ }^{52}$ Algunas investigaciones tradicionales sobre el teatro anarquista se han centrado en el análisis de las obras de dramaturgos pertenecientes o afines al colectivo, sin considerar experiencias que se alejaran del denominado "drama libertario". Eva Golluscio de Montoya, "Elementos para una 'teoría' teatral libertaria (Argentina 1900)”. Latin American Theathre review, Fall (1987), 85-93. Carlos Fos “Palabras preliminares”, en En las tablas libertarias. Experiencias de teatro anarquista en Argentina a lo largo del siglo XX. Editado y compilado por Lorena Verzero (Buenos Aires: Atuel, 2010). Carlos Fos “La red de producción ácrata: Dos acólitos en acción”, en En las tablas libertarias. Experiencias de teatro anarquista en Argentina a lo largo del siglo XX editado y compilado por Lorena Verzero (Buenos Aires: Editorial Atuel, 2010).

53 Suriano, "Banderas, héroes y fiestas proletarias". 
tradición de conmemoración en lugar de festejo. Sin embargo, sostenemos que aunque las veladas artísticas abarcaban dimensiones recreativas, no por ello perdían su carácter político, acercándonos a lo sostenido por Dora Barrancos respecto a las veladas-conferencias desarrolladas por los anarquistas de principios de siglo XX, eventos que cumplían la triple función de propaganda, educación y entretenimiento ${ }^{54}$.

Asimismo algunos de los componentes de las veladas que describimos se replicaban año a año, conduciéndonos a postular su reiteración como elementos que configuraban un ritual. En efecto, la fecha para su realización era siempre un 30 de abril, el evento se efectuaba en un mismo espacio - el salón de actos-, en el mismo horario designado de las 21 horas, respetándose una misma estructura interna en su desarrollo, en ocasiones con leves variaciones, pero contando con los mismos componentes internos: recitados-obra-conferencia-recital de guitarras. Dichos elementos daban forma a un ritual que incluía tanto a los organizadores como a los asistentes, creando un espacio de distensión y sociabilidad, religando y fortaleciendo sus lazos de camaradería, y otorgando visibilidad hacia el resto de la arena política local.

\section{Las funciones a beneficio}

Prosiguiendo con el análisis de la labor del grupo filodramático, observamos que desempeñaban su labor artística realizando sus funciones a beneficio. Resulta pertinente destacar que mediante estas funciones se recaudaba dinero para colaborar tanto con alguna institución local, con gremios que lo necesitaran, o bien con la Biblioteca de la que formaban parte. Nos interesan estas intervenciones, pues a través de ellas se pueden examinar la articulación horizontal que conectaba al grupo filodramático y sus puestas en escena con los diversos sectores de la comunidad a los que iba dirigida la ayuda, observando en ellas su vínculo con el mundo obrero y el activismo anarquista de la época.

El modo en que se desempeñaban los miembros en esas funciones -al igual que en el resto de sus actuaciones- era ad honorem, desarrollando sus actividades actorales de manera amateur, pues su actividad no estaba profesionalizada. Así lo retrata el siguiente testimonio:

Las funciones teatrales que realizábamos tenían invariablemente carácter benéfico. En ocasiones el producido se entregaba a la biblioteca para la compra de libros; otras veces a la Unión Obrera Local para financiar el

${ }^{54}$ Barrancos, "Anarquismo, educación y costumbres". 
periódico, o también se ayudaba a algún gremio en huelga. Lo real es que cuantos desempeñábamos esa actividad lo hacíamos honorariamente ${ }^{55}$.

Como lo plasmábamos en las páginas precedentes, la primera actuación del grupo filodramático fue en efecto, una función a beneficio en el año 1939, en el marco de la campaña para la liberación de los presos de Bragado, cuando se organizó una función teatral para "hacer propaganda y reunir fondos" ${ }^{\text {" } 6}$ en el Teatro Colón de la ciudad.

En el año 1940, ya conformado como agrupación pero sin contar aún con un espacio en el cual desarrollar sus ensayos y funciones, se realizó una función a beneficio de los refugiados españoles en Francia, cuando "el novel conjunto 'Amigos del Arte' ha prestado su concurso para la velada que con ese fin patrocina la Unión Obrera Local, llevándose a cabo mañana a las 21.30 en la sala del Teatro Colón una velada teatral" 57 .

Los resultados de la velada se dieron a conocer unos días más tarde detallándose los gastos y el monto recaudado del siguiente modo "INGRESOS: total de entradas vendidas, \$752, Salidas: alquiler del teatro, 120; Maquinista, 10; Derechos de autor, 9; Impuesto Municipal, 6.30; Imprenta, 36.50; Reparto de propaganda, 5; Género para vestido, 2; Beneficio Líquido, 563.20"58. Del "total de entradas vendidas" puede inferirse el grado de asistencia al evento considerando que las mismas tenían un valor de $\$ 1$, y cuyo balance nos indicaría una gran concurrencia al mismo.

Un evento similar se organizaba en noviembre de 1942 cuando en el salón de actos de la biblioteca se realizaba una función para colaborar con "la 'Coordinadora de Ayuda a los perseguidos por la reacción internacional', patrocinada por la Unión Obrera Local” 59 .

Si bien en la difusión de las actividades de Amigos del Arte siempre se caracterizaba a sus eventos como funciones a beneficio, la ayuda y vinculación con entidades externas a la BPJMy la Casa del Pueblo se intensificó desde 1943, cuando el salón de actos es inhabilitado. En efecto, durante ese año un miembro del comisionado municipal es enviado a inspeccionar el salón, decidiendo clausurarlo debido al carácter precario de sus instalaciones, particularmente la

\footnotetext{
${ }^{55}$ Woollands, Recuerdos de un militante anarquista, 42.

${ }^{56}$ Ibíd., 36.

57 “Periódico El Trabajo”, 01/11/1940.

58 “Periódico El Trabajo”, 12/11/1940.

59 “Periódico El Trabajo”, 14/11/1942.
} 
ausencia de un escenario fijo, pues contaban con uno conformado por tablones y caballetes desmontables ${ }^{60}$.

Luego de la clausura, en 1944, las funciones a beneficio comienzan a operar como un nexo y como un recurso para Amigos del Arte, pues dicho vínculo con las entidades locales o pertenecientes a ciudades aledañas permitían, mediante su patrocinio, la realización de su actividad generando el impulso necesario al carecer de un espacio habilitado.

En el marco que suponían estas funciones su ayuda iba dirigida en primer término hacia la BPJMy “su caja social", pues importaban una ayuda económica valiosa para la tarea cultural y sindical de la casa, dado el carácter ad honorem de quienes conformaban el grupo. Así sucedía hacia julio de 1944, cuando se realizan dos funciones consecutivas, pautadas para la tarde y la noche del sábado 17 y el domingo 18 de ese mes. En esta ocasión se alquilaba el teatro Colón, donde el conjunto filodramático "renovaría el programa" ${ }^{61}$, es decir, presentaría una obra distinta en cada día. También durante 1945 se realizaba "en el cine teatro Odeón una velada teatral organizada por el Sindicato Obreros de la Industria del Pescado a total beneficio de la Biblioteca Popular Juventud Moderna” ${ }^{62}$, mostrando más indicios de la relación estrecha entre dicho sindicato y la agrupación.

Por citar un ejemplo más, en 1946 se realizó una velada teatral cuyo precio era, como era habitual, de $\$ 1$ "destinándose lo producido líquido (sic) a la construcción del escenario de la Casa del Pueblo" ${ }^{63}$.

Estas funciones también se dirigían a ayudar a instituciones de otras ciudades con afinidades políticas o culturales, como sucedía en mayo de 1946 cuando la agrupación artística se presentaba en el cine de la ciudad de Necochea a beneficio de la incipiente Unión Obrera Local de esa cercana localidad ${ }^{64}$. Un mes más tarde y también en un pueblo próximo a Mar del Plata, se realizaba una función teatral para beneficiar a la biblioteca popular de Miramar ${ }^{65}$, funciones que el órgano difusor de la Unión Obrera Local mencionaba de la siguiente manera:

\footnotetext{
60 “Actas comisión administrativa BPJM", 5/08/1943, tomo II, 241.

61 “Periódico El Trabajo”, 17/07/1944.

62 "Periódico El Trabajo", 13/08/1945.

63 "Periódico El Trabajo", 08/11/46.

64 "Periódico El Trabajo”, 03/05/1945.

65 “Periódico El Trabajo”, 18/06/1945.
} 
la agrupación artística amigos del arte paso a paso va cumpliendo la finalidad que le dieron sus fundadores contribuir modestamente a la superación del pueblo y poner al servicio de las entidades e instituciones de carácter benéfico que estén desligadas de banderismos y tendencias en pugna con los principios que constituyen el sentir uniforme del pueblo: la libertad ${ }^{66}$.

La cita precedente nos invita a volver sobre el apoyo brindado a las campañas nacionales e internacionales ligadas al frente republicano en la Guerra Civil española, o bien a "los perseguidos por la reacción internacional", retomando para ello los aportes de Andrés Bisso sobre la labor del Socialismo en la provincia de Buenos Aires en un periodo temporal similar al nuestro. En efecto, el autor sostiene que el antifascismo funcionó allí "no sólo como arma de combate ideológico, sino también como eficaz motor de movilización política y marco diseñador de renovadas experiencias de sociabilidad local" ${ }^{67}$. A este respecto, durante los primeros años de la II Guerra Mundial la acción antifascista se unió a las manifestaciones en defensa de los presos de Bragado, cuya causa había sido reabierta en esos años, de la que también participaba la "Comisión Nacional de Solidaridad Internacional Antifascista”. En ese contexto y como sostiene López Trujillo “(...) la FACA, como el Partido Comunista, el Socialista Obrero, el Socialista y otras fuerzas de izquierda, vieron en el movimiento de solidaridad con España una oportunidad única para la propaganda y la captación política”68. El anarquismo en particular realizó intentos por coordinar acciones entre los distintos sectores dentro de su movimiento, mediante la Comisión Nacional de Solidaridad Internacional Antifascista (SIA), organismo creado por la FACA y desde el que se convocó a distintos grupos y personalidades antifascistas de renombre ${ }^{69}$.

De lo expuesto podemos sostener en primer término, que el apoyo a dichas campañas ayudó a vitalizar la actividad artística de la agrupación, tratándose de funciones desarrolladas durante los primeros años de su desempeño, en

66 “Periódico Unión Obrera Local”, Mar del Plata, Junio de 1945, (ABPJM).

${ }^{67}$ Andrés Bisso, "Mímicas de guerra, costumbres de paz. Las prácticas de movilización antifascista del Partido Socialista en el interior bonaerense durante la Segunda Guerra Mundial (1939-1945)", en X Jornadas Interescuelas/Departamentos de Historia (Escuela de Historia de la Facultad de Humanidades y Artes, Universidad Nacional del Rosario. Rosario, 2005), 1.

68 López, "Vidas en rojo y negro", 186.

${ }^{69}$ Ibíd. 
el lapso que transcurre desde 1939 a 1942. En segundo lugar, más allá de la ayuda brindada por Amigos del Arte a esas movilizaciones en particular, al indagar en el trasfondo político de esos años observamos la presencia de elementos que remiten a causas políticas con proyección nacional y que, indefectiblemente, revisten una ligazón con "banderismos y tendencias en pugna”, pues se alineaban con tácticas de acción provenientes de entidades u organizaciones con las que la BPJM y la UOL se encontraban relacionadas en ámbitos que superaban lo local.

Por otro lado, y aunque las funciones a beneficio tendían lazos con el mundo político y gremial de esos años, también lo hacían con organismos que no pertenecían a ese universo, arrojando sentidos divergentes con respecto a su labor cultural. Así sucedía en julio de 1946 cuando se realizaba una función a beneficio del Centro de higiene maternal e infantil de Mar del Plata, función organizada por la comisión de damas de ese centro de salud ${ }^{70}$, una "sociedad de beneficencia" de señoras que no tenía relación aparente con el activismo y mundo obrero de esos años. Ese hecho consideramos, muestra además de un perfil abierto en el grupo filodramático al momento de realizar esta modalidad de funciones, un carácter disruptivo respecto a cierto "sentido común" sobre el anarquismo presente en la literatura y las investigaciones más tradicionales que abordan el tema. También nos invita a plantear como posibilidad que esa vinculación "atípica" se daba en el marco de vínculos antiperonistas, teniendo en cuenta el afamado enfrentamiento entre Eva Perón y las sociedades de beneficencia encabezadas por las damas de la oligarquía nacional acometido por esos años.

Sintetizando, observamos que las funciones a beneficio operaban como motivación y "pretexto" para el conjunto filodramático y su labor, más allá de sus fines explícitos de recaudar dinero para colaborar con diversas entidades. Así sucedía cuando por ejemplo, ocurre la clausura del salón de actos y la periodicidad en la realización de funciones aumenta, operando como un factor que estimulaba y posibilitaba su actividad al carecer de un espacio idóneo; o como también durante sus primeros años de desempeño cuando la ligazón con causas o campañas más generales ligadas al antifascismo operaba como un aliciente para el despliegue de sus actividades, revelando el trasfondo político en ese período.

\section{Conclusiones}

A lo largo del presente trabajo hemos rastreado mediante el análisis de la trayectoria de Amigos del Arte las superposiciones entre las distintas

70 “Periódico El Trabajo”, 27/06/1945. 
actividades que tomaban parte dentro de la BPJM, una asociación que contaba con propósitos explícitos ligados a su labor cultural y gremial, pero que también generaba espacios para la sociabilidad, la reunión y el esparcimiento.

Observamos en efecto, a través de la pertenencia múltiple de los actores y actrices del grupo filodramático cómo se establecían los vínculos entre esos espacios de participación disímiles, al tiempo que coexistentes dentro de la misma institución. Juventudes Libertarias, UOL, grupo filodramático, biblioteca, eran lugares transitados por igual por los jóvenes militantes que conformaron el grupo teatral, muchas veces interceptados entre sí por vínculos familiares y de amistad.

El análisis de las veladas de Primero de mayo reveló la importancia otorgada a la conmemoración de esa efeméride, pero también nos arrojó sentidos disruptivos con respecto a lecturas más ortodoxas sobre la fecha. En ese sentido, se remarcó las críticas que el movimiento anarquista históricamente había esgrimido respecto a la caracterización como festividad por parte de las otras fuerzas dentro de la izquierda, y como en nuestro caso, dicha conmemoración no estaba exenta de elementos festivos. Las veladas artísticas en efecto, constituían un evento en el que la recreación, el ocio, el esparcimiento y la diversión no iban en detrimento de su carácter político, aspecto anclado en el reforzamiento de sus lazos de camaradería mediante la reiteración de componentes rituales, y en la adquisición de visibilidad en la arena política local para la atracción de nuevos militantes.

Por otro lado las funciones a beneficio mostraron la vinculación del grupo filodramático con causas o instituciones que les eran afines, en ocasiones conectándose con campañas de dimensión nacional e internacional, así como también con instituciones o agrupaciones que en apariencia no se relacionaban del todo con su campo de acción. Asimismo, estas funciones nos permitieron observar el posicionamiento general de la asociación con respecto al panorama político nacional e internacional, primero de la mano de las campañas apoyadas dentro del antifascismo - posicionamiento alineado con la política que la FACA desarrollaba en torno a ese tópico- y luego, aunque no lo hemos indagado en profundidad, en contra de la hegemonía que el peronismo iba construyendo con respecto a los sectores obreros y populares.

De este modo, hemos utilizado a la actividad teatral de Amigos del Arte como un prisma con el cual pudimos acceder a la vida social, política y cultural de una institución que, aunque tradicional dentro del mundo obrero y activismo marplatense, mostraba indicios de adaptación a las transformaciones más 
generales que se estaban imponiendo. Mencionamos en ese sentido los cambios en las lecturas efectuadas por la UOL en torno a la intervención estatal de la mano de su alineamiento con la FACA, o bien las modificaciones efectuadas por la comisión administrativa para ajustarse a los requerimientos legales que se estaban aplicando, como la adquisición de personería jurídica, la modificación de sus estatutos, la incorporación de menores de edad a la categoría de socios, etc.

Planteamos como ejes posibles para el desarrollo de investigaciones futuras el análisis del tipo de material bibliográfico consultado por los miembros del grupo filodramático, así como su comparación con los textos dramáticos representados en sus funciones teatrales; el análisis comparativo de otros grupos filodramáticos que tuvieron presencia en la institución durante otros períodos históricos; la vida de la biblioteca en los años posteriores al periodo de análisis aquí delimitado, así como la trayectoria de los actores y actrices vocacionales que hemos investigado con posterioridad a 1947, entre otros temas de interés.

\section{Referencias bibliográficas}

\section{Fuentes primarias}

\section{Manuscritas}

Archivo Biblioteca Popular Juventud Moderna (ABPJM), Mar del Plata, Argentina. Actas de la comisión administrativa de la institución. Tomo I: actas correspondientes al periodo 1931-1943. Tomo II: actas correspondientes al periodo 1946-1951.

\section{Publicaciones periódicas}

Archivo Biblioteca Popular Juventud Moderna (ABPJM), Mar del Plata, Argentina. Periódico Unión Obrera Local, ediciones correspondientes al periodo 1945-1947 (versión digitalizada por Agustín Nieto).

Archivo Histórico Municipal General Pueyrredón (AHMGP), Mar del Plata, Argentina. Hemeroteca, Periódico “El Trabajo”, ediciones de enero de 1939 a diciembre de 1947.

\section{Fuentes secundarias}

Barrancos, Dora. Anarquismo, educación y costumbres en la Argentina de principios de siglo. Buenos Aires: Editorial Contrapunto, 1990.

Bisso, Andrés. "Mímicas de guerra, costumbres de paz. Las prácticas de movilización antifascista del Partido Socialista en el interior bonaerense durante la Segunda Guerra Mundial (1939-1945)”, En X Jornadas Interescuelas/Departamentos de Historia. Escuela de Historia de la Facultad de Humanidades y Artes, Universidad Nacional del Rosario. Rosario, 2005. 
Bordagaray, María Eugenia. “Controversias libertarias: La interpelación anarquista en tiempos del anarquismo”. Tesis de posgrado, Universidad Nacional de La Plata, Facultad de Humanidades y Ciencias de la Educación, 2014.

Da Orden, María Liliana. ¿¿Prácticas tradicionales en un partido moderno? Socialismo y poder local, Mar del Plata, 1916-1929”. La construcción de las democracias Rioplatenses Proyectos institucionales y prácticas políticas, 1900-1930, editado por Fernando Devoto y María Ferrari. Buenos Aires: Editorial Biblos, 1994, 229-246.

Dolabani, Milagros. "El teatro en los festejos anarquistas del primero de mayo: entre la conmemoración y el ocio recreativo (Mar del Plata, 1939-1947)”. Revista Izquierdas, n. 36 (2017): 181-199. URL: http://www.izquierdas.cl/images/html/ n36/index36.html

Dolabani, Milagros. "El repertorio teatral de Amigos del Arte: entre la "cultura anarquista' y la 'cultura de masas'. Mar del Plata 1939-1947”, Revista Páginas 9, n. 20 (2017): $147-168$.

Dorado, Gustavo, Lucas González y Oscar Spadari. Entre bibliotecasy andamios. Orígenes del movimiento obrero en Mar del Plata (1890-1930). Mar del Plata: Suárez, 2013

Fos, Carlos. "Palabras preliminares". En En las tablas libertarias. Experiencias de teatro anarquista en Argentina a lo largo del siglo XX. Editado y compilado por Lorena Verzero. Buenos Aires: Atuel, 2010.

Fos, Carlos. "La red de producción ácrata: Dos acólitos en acción”. En En las tablas libertarias. Experiencias de teatro anarquista en Argentina a lo largo del siglo XX. Editado y compilado por Lorena Verzero. Buenos Aires: Atuel, 2010.

Golluscio de Montoya, Eva. "Elementos para una 'teoría teatral libertaria (Argentina 1900)". Latin American Theathre review, Fall (1987): 85-93.

Graciano, Osvaldo. "La escritura de la realidad. Un análisis de la tarea editorial y del trabajo intelectual del Anarquismo argentino entre los años 30 y el Peronismo”. Revista Izquierdas, n. ${ }^{\circ} 12$ (2012): 72-110. URL: http://www.izquierdas.cl/ediciones/2012/numero-12-abril.

López Trujillo, Fernando. Vidas en rojo y negro. Una historia del anarquismo en la "Década infame”. Buenos Aires: Letra libre, 2005.

Migueláñez Martínez, María. "1910 y el declive del anarquismo argentino. ¿Hito histórico o hito historiográfico?”. XIV Encuentro de Latinoamericanistas Españoles: congreso internacional, Santiago de Compostela, España. Compilado por Rey Tristán, Eduardo y Calvo González, Patricia. Universidad de Santiago de Compostela, Centro Interdisciplinario de Estudios Americanistas Gumersindo Busto, Consejo Español de Estudios Iberoamericanos, Sciences de l'Homme et de la Société (2010): 436-452. URL: https://halshs.archives-ouvertes.fr/halshs-00529699

Nieto, Agustín. "Conflictividad obrera en el puerto de Mar del Plata: del anarquismo al peronismo. El Sindicato Obrero de la Industria del Pescado, 1942-1948”. Revista de Estudios Marítimos y Sociales n. ${ }^{\circ} 1$ (2008): 35-44.

Nieto, Agustín. "Notas críticas en torno al sentido común historiográfico sobre 'el anarquismo argentino". A contra corriente. vol 7, n. 3 (2010): 219-248.

Nieto, Agustín. "Anarquistas negociadores. Una revisión del sentido común historiográfico sobre el 'anarquismo argentino' a la luz de algunas experiencias libertarias 
en el movimiento obrero, Mar del Plata 1940-1943”. En Taller de la Historia, vol. 5 , n. 5 (2013): 245-277.

Nieto, Agustín “Un acercamiento ‘topográfico’ a la militancia” sindical libertaria en la Argentina de los años cuarenta 187-216”, Anuario digital n. ${ }^{\circ} 24$ (2012).

Nieto, Agustín. "Asociacionismo obrero y popular en la aldea, Mar del Plata (19401960)". En Asociaciones y política en la Argentina del siglo XX. Entre prácticas y expectativas. Editado por Omar Acha y Nicolás Quiroga. Buenos Aires: Prometeo Libros, 2015, 179-201.

Pastoriza, Elisa. Los trabajadores de Mar del Plata en vísperas del peronismo. Buenos Aires: Centro editor de América Latina, 1993.

Quiroga, Nicolás. "Lectura y política. Los lectores de la biblioteca popular juventud moderna de Mar del Plata (fines de los años treinta y principios de los cuarenta)”. Anuario IEHS n. ${ }^{\circ} 18$ (2003): 449-474.

Quiroga, Nicolás. "Prácticas políticas y cambio cultural: anarquistas autodidactas hacia mediados de 1940". Estudios Ibero-americanos, vol. 30, n. 1 (2004): 139-160.

Revel, Jacques. Juegos de escala. Experiencias de microanálisis. Buenos Aires: UNSAM edita, 2015.

Suriano, Juan. "Banderas, héroes y fiestas proletarias. Ritualidad y simbología anarquista a comienzos de siglo”, Boletín número 15 del Instituto de historia argentina y americana Dr. Emilio Ravignani 3ra serie (Universidad de Buenos Aires: Fondo de Cultura Económica, 1er semestre de 1997), 71-100.

Suriano, Juan. "Las prácticas culturales del anarquismo argentino", Trabajo presentado en el Encuentro Cultura y Práctica del Anarquismo, desde sus orígenes hasta la Primera Guerra Mundial, Cátedra México-España del Colegio de México, 23 y 24 de marzo de 2011, "Federación Libertaria Argentina" (2011). URL: http://www. federacionlibertaria.org/BAEL/Archivo/Tesis, \%20monografias/Suriano\%20 $=\% 20 \operatorname{Pr} \%$ C $3 \%$ A1cticas $\% 20$ culturales $\% 20-\% 20$ Argentina.pdf. Consultado el 21 de mayo de 2018.

Suriano, Juan. "La reforma electoral de 1912 y la impugnación anarquista”. Estudios sociales, vol.43, n. 1 (2012): 91-104.

Tarcus, Horacio. "Las izquierdas argentinas en el siglo XX. Una aproximación metodológica”. En Aportes para una Argentina plural. Buenos Aires: Archivo General de la Nación, 1999, 97-115.

Verzero, Lorena. "Hacia una historia material de las prácticas teatrales anarquistas". En En las tablas libertarias. Experiencias de teatro anarquista en Argentina a lo largo del siglo XX. Editado y compilado por Lorena Verzero sobre textos de Carlos Fos. Buenos Aires: Atuel, 2010.

Verzero, Lorena. "Políticas de la investigación en teatro político". Territorio teatral revista digital $\mathrm{n}^{\circ} 9$ (2013): $1-8$.

Woollands, Héctor. Notas para la historia de la Biblioteca Popular Juventud Moderna. Mar del Plata: Ediciones Biblioteca Popular Juventud Moderna, 1989.

Woollands, Héctor. Recuerdos de un militante anarquista. Mar del Plata: Grupo Editor el Martillo, 1999. 